\title{
Expression of doublecortin and CaM kinase-like-1 protein in serrated neoplasia of the colorectum
}

\author{
KEIKO MORIO, KAZUO YASHIMA, AKIHIRO TAMOTO, KOHEI HOSODA, SOHEI YAMAMOTO, \\ TAKU IWAMOTO, NAOKI UEDA, YUICHIRO IKEBUCHI, KOICHIRO KAWAGUCHI, \\ KENICHI HARADA, YOSHIKAZU MURAWAKI and HAJIME ISOMOTO
}

Division of Medicine and Clinical Science, Faculty of Medicine, Tottori University, Yonago, Tottori 683-8504, Japan

Received October 10, 2017; Accepted October 30, 2017

DOI: 10.3892/br.2017.1017

\begin{abstract}
The adenoma-carcinoma sequence (ACS) and the serrated pathway are two distinct developmental routes leading to the formation of colorectal carcinoma. Recently, the doublecortin and CaM kinase-like-1 protein (DCLK1) has been reported to serve as an intestinal cancer stem cell marker and has been demonstrated to be overexpressed through the ACS; however, there is a lack of reports on the role of DCLK1 in the serrated pathway. To clarify the correlation between DCLK1 protein expression and clinicopathological characteristics of the serrated tumorigenic pathway, the present study used immunohistochemistry to examine the expression of DCLK1 in endoscopically resected samples of 62 serrated polyps [20 hyperplastic polyps (HPs), 16 traditional serrated adenomas (TSAs) and 26 sessile serrated adenoma-polyps (SSA/Ps)], as well as 20 non-serrated adenomas, 20 carcinoma in adenomas (CIAs) and 18 early pure colorectal carcinomas without any adenoma component (EPCs). Based on immunostaining score, high DCLK1 expression was detected in $20.0 \%$ of HPs (23.1\% of microvesicular HPs and $14.3 \%$ of goblet cell HPs), $37.5 \%$ of TSAs, $7.7 \%$ of SSA/Ps, $80.0 \%$ of non-serrated adenomas, $75.0 \%$ of CIAs and $50.0 \%$ of EPCs. Negative or low DCLK1 expression was frequently observed in TSAs $(\mathrm{P}<0.005)$, SSA/Ps $(\mathrm{P}<0.00001)$ and EPCs $(\mathrm{P}<0.04)$ compared with non-serrated adenomas and CIAs. In addition, negative or low DCLK1 expression was significantly more frequent in SSA/Ps $(92.3 \%)$ compared with TSAs $(62.5 \%$; $\mathrm{P}<0.05)$. Thus, the expression pattern of DCLK1 between the serrated pathway and ACS differed, indicating that DCLK1 expression may perform a secondary role in serrated tumorigenesis. In addition, the data indicates that EPCs may contain tumors derived from the serrated pathway as well as the ACS.
\end{abstract}

Correspondence to: Dr Kazuo Yashima, Division of Medicine and Clinical Science, Faculty of Medicine, Tottori University, 36-1 Nishicho, Yonago, Tottori 683-8504, Japan

E-mail: yashima@med.tottori-u.ac.jp

Key words: doublecortin and CaM kinase-like-1, serrated pathway, serrated adenoma-polyps, endoscopic resection

\section{Introduction}

Colorectal cancer (CRC) is among the most common types of malignancy in the United States, with a lifetime prevalence of $\sim 5 \%$ (1). It is proposed by the adenoma-carcinoma sequence (ACS) model that the carcinoma arises from a pre-existing adenoma (2). The serrated pathway to CRC formation, in which serrated polyps develop into cancer, has been proposed as an alternative route to colorectal carcinogenesis $(3,4)$. According to the 2010 World Health Organization (WHO) classification (5), serrated polyps may be categorized as hyperplastic polyps (HPs), sessile serrated adenoma-polyps (SSA/Ps) or traditional serrated adenomas (TSAs).

Doublecortin and CaM kinase-like-1 protein (DCLK1, also known as DCAMKL1) is a microtubule-binding member of the calmodulin-dependent kinase family that serves important roles in the regulation of cell differentiation, migration and apoptosis, and has also been proposed as a marker for intestinal stem cells and cancer stem cells (6-9). In animal models with xenografted colonic or pancreatic tumors, silencing of the DCLK1 gene resulted in a decrease in tumor size (10-12). Although the precise tumor-promoting mechanism of DCLK1 is yet to be determined, it has been demonstrated that reduced DCLK1 expression correlates with increased expression of tumor suppressor microRNAs (miRs), including miR-145, miR-200 and let-7a $(11,12)$. Indeed, DCLK1 has been indicated to function as an oncogene in several types of tumor, including CRC (13-15), pancreatic cancer (8), hepatocellular carcinoma (16), gastric cancer (17) and Barrett's adenocarcinoma (18).

To the best of our knowledge, no previous study has comprehensively measured the expression of DCLK1 in serrated and non-serrated colorectal neoplasias. In the current study, to clarify the molecular and clinicopathological characteristics of the serrated tumorigenic pathway, immunohistochemistry was used to evaluate DCLK1 expression in 120 endoscopically-resected samples of serrated and non-serrated colorectal neoplasias.

\section{Materials and methods}

Patient samples. As described in our previous study on fragile histidine triad and cyclooxygenase-2 expression in serrated 
neoplasia (19), tumor specimens were obtained from 120 patients (90 males and 30 females; mean age, 66.1 11.5 years), who had undergone endoscopic resection at Tottori University Hospital (Tottori, Japan) between January 2009 and December 2014. The samples included $20 \mathrm{HPs}, 16$ TSAs and 26 sessile serrated adenoma/polyps (SSA/Ps), making a total of 62 serrated polyps, as well as 20 non-serrated adenomas, 20 carcinoma in adenomas (CIAs) and 18 early pure colorectal carcinomas without any adenoma component (EPCs). Patients with familial adenomatous polyposis (FAP), hereditary nonpolyposis CRC (HNPCC) or hyperplastic polyposis (HPP) were excluded from the study. Serrated lesions (HPs, SSAs and TSAs) were classified on the basis of WHO criteria (5). The 20 HPs were subdivided into ten microvesicular HPs (MVHPs) and ten goblet cell HPs (GCHPs). Non-serrated adenomas measuring $>10 \mathrm{~mm}$ were used for the study. All histological types of CIAs and EPCs were well-differentiated adenocarcinomas. In addition, these neoplasms were confined to the mucosa or submucosa. Histological evaluations were performed according to the classification established by the Japanese General Rules for Clinical and Pathological Studies on Cancer of the Colon, Rectum and Anus (20). In the study, non-serrated adenoma samples corresponded to low- or high-grade adenoma/dysplasia, and CIA and EPC samples of mucosa and submucosa corresponded to non-invasive carcinoma or intramucosal and submucosal carcinoma according to the Vienna classification system (21). Tumors were divided into polypoid, and flat or depressed groups on the basis of their morphological features. Flat and depressed tumors were defined as having endoscopically visibly flat or depressed mucosal lesions, with a height measuring $>50 \%$ of their diameter (22). All other tumorous lesions in the colon were termed polypoid lesions. The clinical characteristics of the patients are reported in our previous study (19). All cases were de-identified prior to analysis, and written informed consent was obtained from all patients. The study was approved by the Institutional Review Board of Tottori University and was conducted in accordance with the Declaration of Helsinki.

Immunohistochemical staining. Immunohistochemical staining was performed on paraffin-embedded 5-mm sections following fixation in $10 \%$ formalin overnight at room temperature. All sections were immunohistochemically stained with rabbit polyclonal anti-DCLK1 antibody (ab37994; dilution 1:80; Abcam, Cambridge, MA, USA). Heat-induced epitope retrieval was performed in citrate buffer ( $\mathrm{pH}$ 6.0) using a microwave oven at $99^{\circ} \mathrm{C}$. Primary antibody incubation was carried out overnight at $4^{\circ} \mathrm{C}$. Detection was performed with a Vectastain Elite ABC kit (Vector Laboratories, Inc., Burlingame, CA, USA) according to the manufacturer's instructions. As a negative control, the primary antibody was replaced with serum immunoglobulin G (GTX35035; GeneTex, Inc., Irvine, CA, USA) at the same dilution. A CIA sample from the total cohort exhibiting strong intensity immunostaining for DCLK1, defined by the staining evaluation method of a previous study (13), was used as a positive control. For each specimen, at least five fields were viewed under a light microscope (magnification, x100; Olympus Corporation, Tokyo, Japan). Immunohistochemical staining of DCLK1 expression was analyzed by two independent observers blinded to the clinical information.
Assessment of DCLK1 immunostaining. The extent (or proportion) of DCLK1 staining was scored as: 0 ( $<5 \%$ positive cells), 1 (5-30\% positive cells), 2 (31-60\% positive cells) or 3 (61-100\% positive cells); the staining intensity was scored as: 0 (negative), 1 (mild), 2 (moderate) or 3 (strong), as previously described (13). The final score was determined from the combination of the staining intensity and proportion scores. Negative expression of DCLK1 was defined as a combined score of $0-1$; low expression was defined as a combined score of 2-3; and high expression was defined as a combined score of 4-6 (13).

Statistical analysis. Statistical analysis was performed using the Fisher's exact test, $\chi^{2}$ test with Yates' correction or Mann-Whitney U test. $\mathrm{P}<0.05$ was considered to indicate statistical significance. All statistical calculations were performed using Stat Flex (version 6.0; Artech Co., Ltd., Osaka, Japan).

\section{Results}

Clinicopathological features. The clinicopathological characteristics of the patients are reported in our previous study (19).

DCLK1 expression in early colorectal neoplasms. The results of the immunohistochemical staining experiments are presented in Fig. 1 and Table I. High DCLK1 expression was detected in $20.0 \%$ of HPs $(23.1 \%$ of MVHPs and $14.3 \%$ of GCHPs), $37.5 \%$ of TSAs, $7.7 \%$ of SSA/Ps, $80.0 \%$ of non-serrated adenomas, $75.0 \%$ of CIAs and $50.0 \%$ of EPCs. Negative or low DCLK1 expression was frequently observed in HPs $(\mathrm{P}<0.0001)$, TSAs $(\mathrm{P}<0.005)$, SSA/Ps $(\mathrm{P}<0.00001)$ and EPCs $(\mathrm{P}<0.04)$ compared with non-serrated adenomas and CIAs. In addition, negative or low DCLK1 expression was significantly more frequent in SSA/Ps (92.3\%) compared with TSAs $(62.5 \%$; $\mathrm{P}<0.05)$. High DCLK1 expression was more common in non-serrated adenomas $(80.0 \%)$ compared with serrated polyps $(19.4 \%$; $\mathrm{P}=0.01)$. Furthermore, high DCLK1 expression was more frequent in CIAs $(75.0 \%)$ compared with EPCs $(50.0 \%$; $\mathrm{P}=0.10)$. Potential associations between protein expression and clinicopathological data (age, sex, tumor size, tumor location, macroscopic features, depth of invasion and lymphatic and venous invasion) were also analyzed; however, no significant associations were observed.

\section{Discussion}

The ACS and the serrated pathway are two distinct models that explain the development of colorectal neoplasms $(3,23)$. Serrated colorectum polyps exhibit distinct histological features and malignant potential (3). CRCs arising from the serrated pathway are also frequently associated with aberrant patterns of promoter methylation (4), a phenotype discussed further below. Previous reports have suggested that DCLK1 may mark cancer stem cells in gastrointestinal and other cancers $(10,24)$, while others have identified DCLK1 upregulation in several types of cancer, including esophageal, stomach, colorectal, pancreatic and liver cancer (8,13-18). In addition, increased DCLK1 expression has been identified in Barrett's esophagus, a premalignant lesion that can progress to esophageal adenocarcinoma, and may be regarded as an 
Table I. DCLK1 expression in early colorectal neoplasms.

\begin{tabular}{lcrc}
\hline & & \multicolumn{2}{c}{ DCLK1 expression, $\mathrm{n}(\%)$} \\
\cline { 3 - 4 } Neoplasm type & Sample size, $\mathrm{n}$ & Negative or low & High \\
\hline GCHP & 7 & $6(85.7)^{\mathrm{a}}$ & $1(14.3)^{\mathrm{g}}$ \\
MVHP & 13 & $10(76.9)^{\mathrm{a}}$ & $3(23.1)^{\mathrm{g}}$ \\
TSA & 16 & $10(62.5)^{\mathrm{b}}$ & $6(37.5)^{\mathrm{g}}$ \\
SSA/Ps & 26 & $24(92.3)^{\mathrm{c}}$ & $2(7.7)^{\mathrm{g}}$ \\
Adenoma & 20 & $4(20.0)^{\mathrm{d}}$ & $16(80.0)^{\mathrm{h}}$ \\
CIA & 20 & $5(25.0)^{\mathrm{e}}$ & $15(75.0)^{\mathrm{i}}$ \\
EPC & 18 & $9(50.0)^{\mathrm{f}}$ & $9(50.0)^{\mathrm{j}}$ \\
\hline
\end{tabular}

${ }^{\mathrm{a}}$ vs. ${ }^{\mathrm{d}, \mathrm{e}}, \mathrm{P}<0.0001 ;{ }^{\mathrm{b}}$ vs. ${ }^{\mathrm{d}, \mathrm{e}}, \mathrm{P}<0.005 ;{ }^{\mathrm{c}}$ vs. ${ }^{\mathrm{dee}}, \mathrm{P}<0.00001 ;{ }^{\mathrm{f}}$ vs. ${ }^{\mathrm{d}, \mathrm{e}}, \mathrm{P}<0.04 ;{ }^{\mathrm{b}}$ vs. ${ }^{\mathrm{c}}, \mathrm{P}<0.05 ;{ }^{\mathrm{g}}$ vs. ${ }^{\mathrm{h}}, \mathrm{P}=0.01 ;{ }^{\mathrm{i}}$ vs. ${ }^{\mathrm{j}}, \mathrm{P}=0.10 . \mathrm{DCLK} 1$, doublecortin and CaM kinase-like-1; GCHP, goblet cell hyperplastic polyps; MVHP, microvesicular hyperplastic polyps; TSA, traditional serrated adenoma; SSA/Ps, sessile serrated adenoma/polyps; CIA, carcinoma in adenoma; EPC, early pure colorectal carcinoma without adenoma component.
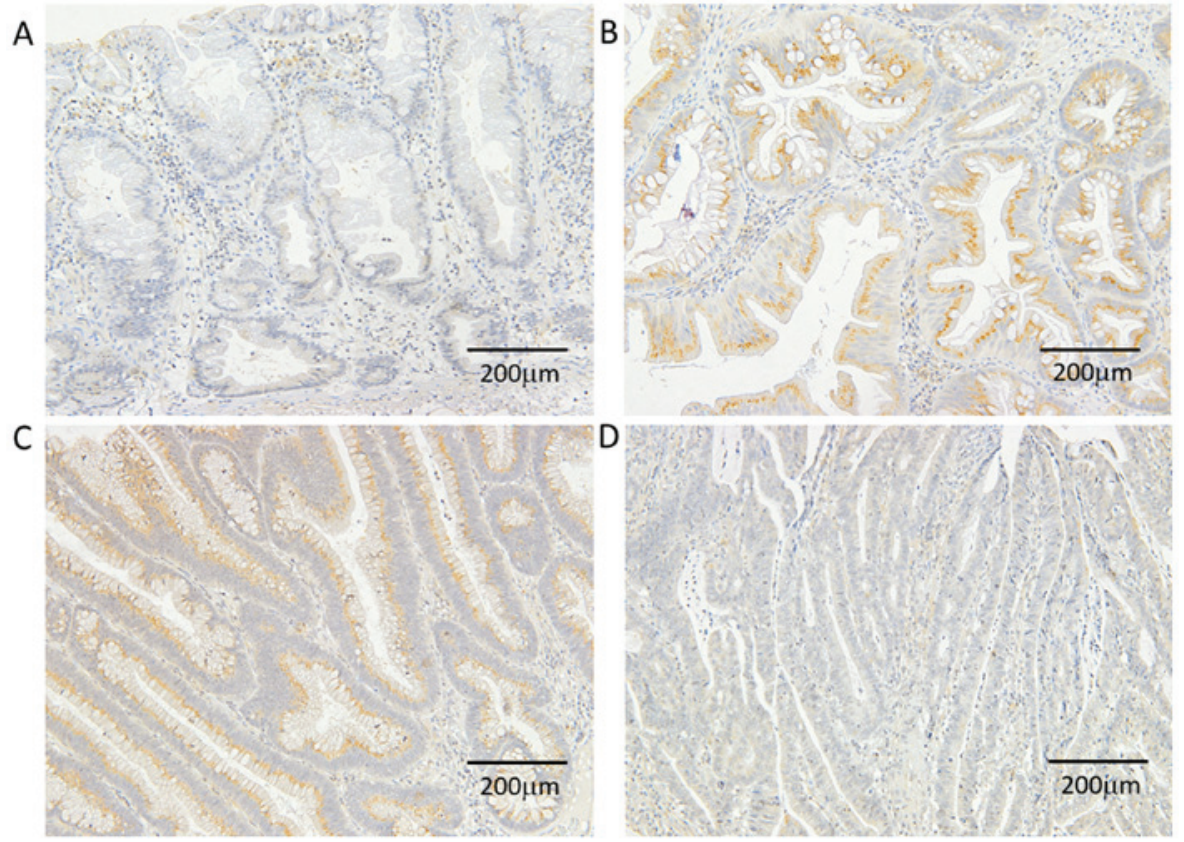

Figure 1. Representative results of DCLK1 immunostaining (brown). (A) Negative immunostaining in sessile serrated adenoma-polyp. (B) High DCLK1 expression in traditional serrated adenoma. (C) High DCLK1 expression in a carcinomatous area of carcinoma in adenoma. (D) Negative immunostaining in early pure colorectal carcinoma without adenoma. Magnification, x200. DCLK1, doublecortin and CaM kinase-like-1.

early molecular predictor of tumor progression (18). Although DCLK1 has been demonstrated to be upregulated in human colorectal adenoma and cancer (13), studies on the expression of DCLK1 in serrated tumor tissue are lacking. Thus, the present study was the first to demonstrate that DCLK1 protein was not overexpressed in serrated tumor tissues.

To the best of our knowledge, no study to date has compared DCLK1 expression levels in SSA/Ps, TSAs, non-serrated adenomas and adenocarcinomas. The present results indicate that negative or low DCLK1 expression is frequent in serrated neoplasias, particularly SSA/Ps, when compared with non-serrated neoplasias. Aberrant crypt foci in the right side of the colon, as a characteristic of MVHP, are a precursor lesion for the SSA/P-cancer sequence (22). In the present study, negative or low DCLK1 expression was detected in $23.1 \%$ of MVHPs. The serrated pathway involves widespread aberrant DNA methylation in promoter regions, a phenomenon termed $\mathrm{CpG}$ island methylator phenotype (4). As promoter methylation is commonly associated with transcriptional repression and subsequent reduction (or loss) of gene function, methylation at the DCLK1 promoter potentially explains the reduced expression observed in serrated polyps $(6,25)$. Therefore, it is possible that DCLK1 overexpression may serve a secondary role in this pathway. In addition, absent or low expression of DCLK1 was significantly more frequent in SSA/Ps (92.3\%) compared with TSAs $(62.5 \%)$, indicating that each serrated tumor type has different molecular features.

Absent or low expression of DCLK1 in EPCs was frequent when compared with non-serrated adenomas and CIAs, and 
had an intermediate frequency between that of non-serrated adenomas/CIAs and serrated polyps, supporting the hypothesis that the molecular pathogenesis of EPC is distinct from that of the ACS regarding the expression of DCLK1. EPCs may therefore contain tumors derived from the serrated pathway as well as the ACS.

In conclusion, in the early developmental stage of the serrated tumors, DCLK1 expression was infrequently detected, unlike the situation in ACS tumors. However, as the number of tumor samples in the current study was limited, further large-scale studies are now required to more precisely determine the role of DCLK1 in serrated tumorigenesis.

\section{References}

1. Siegel R, Ma J, Zou Z and Jemal A: Cancer statistics, 2014. CA Cancer J Clin 64: 9-29, 2014.

2. Vogelstein B, Fearon ER, Hamilton SR, Kern SE, Preisinger AC, Leppert M, Nakamura Y, White R, Smits AM and Bos JL: Genetic alterations during colorectal-tumor development. N Engl J Med 319: 525-532, 1988.

3. Mäkinen MJ, George SM, Jernvall P, Mäkelä J, Vihko P and Karttunen TJ: Colorectal carcinoma associated with serrated adenoma - prevalence, histological features, and prognosis. J Pathol 193: 286-294, 2001.

4. O'Brien MJ, Yang S, Huang CS, Shepherd C, Cerda S and Farraye FA: The serrated polyp pathway to colorectal carcinoma. Diagn Histopathol 14: 78-93, 2008.

5. Snover DC, Ahnen DJ and Burt RW: Serrated polyps of the colon and rectum and serrated polyposis. In: WHO Classification of Tumors of the Digestive System. Bosman FT, Carneiro F, Hruban RH and Theise ND (eds). IARC Press, Lyon, France, pp160-165, 2010

6. May R, Riehl TE, Hunt C, Sureban SM, Anant S and Houchen CW: Identification of a novel putative gastrointestinal stem cell and adenoma stem cell marker, doublecortin and CaM kinase-like-1, following radiation injury and in adenomatous polyposis coli/multiple intestinal neoplasia mice. Stem Cells 26: 630-637, 2008.

7. May R, Sureban SM, Lightfoot SA, Hoskins AB, Brackett DJ, Postier RG, Ramanujam R, Rao CV, Wyche JH, Anant S and Houchen CW: Identification of a novel putative pancreatic stem/progenitor cell marker DCAMKL-1 in normal mouse pancreas. Am J Physiol Gastrointest Liver Physiol 299: G303-G310, 2010.

8. Bailey JM, Alsina J, Rasheed ZA, McAllister FM, Fu YY, Plentz R, Zhang H, Pasricha PJ, Bardeesy N, Matsui W, et al: DCLK1 marks a morphologically distinct subpopulation of cells with stem cell properties in preinvasive pancreatic cancer. Gastroenterology 146: 245-256, 2014.

9. Westphalen CB, Takemoto Y, Tanaka T, Macchini M, Jiang Z, Renz BW, Chen X, Ormanns S, Nagar K, Tailor Y, et al: Dclk1 defines quiescent pancreatic progenitors that promote injuryinduced regeneration and tumorigenesis. Cell Stem Cell 18: 441-455, 2016.

10. Nakanishi Y, Seno H, Fukuoka A, Ueo T, Yamaga Y, Maruno T, Nakanishi N, Kanda K, Komekado H, Kawada M, et al: Dclk1 distinguishes between tumor and normal stem cells in the intestine. Nat Genet 45: 98-103, 2013.
11. Sureban SM,May R, Ramalingam S,Subramaniam D, Natarajan G, Anant S and Houchen CW: Selective blockade of DCAMKL-1 results in tumor growth arrest by a Let-7a MicroRNA-dependent mechanism. Gastroenterology 137: 649-659, 659.e1-659.e2, 2009.

12. Sureban SM, May R, Qu D, Weygant N, Chandrakesan P, Ali N, Lightfoot SA, Pantazis P, Rao CV, Postier RG and Houchen CW: DCLK1 regulates pluripotency and angiogenic factors via microRNA-dependent mechanisms in pancreatic cancer. PLoS One 8: e73940, 2013.

13. Gagliardi G, Goswami M, Passera R and Bellows CF: DCLK1 immunoreactivity in colorectal neoplasia. Clin Exp Gastroenterol 5: 35-42, 2012.

14. Gao T, Wang M, Xu L, Wen T, Liu J and An G: DCLK1 is up-regulated and associated with metastasis and prognosis in colorectal cancer. J Cancer Res Clin Oncol 142: 2131-2140, 2016.

15. Ikezono YU, Koga H, Abe M, Akiba J, Kawahara A, Yoshida T, Nakamura T, Iwamoto H, Yano H, Kage M, et al: High expression of the putative cancer stem cell marker, DCLK1, in rectal neuroendocrine tumors. Oncol Lett 10: 2015-2020, 2015.

16. Sureban SM,Madhoun MF,May R,QuD, Ali N,Fazili J, Weygant N, Chandrakesan P, Ding K, Lightfoot SA and Houchen CW: Plasma DCLK1 is a marker of hepatocellular carcinoma (HCC): Targeting DCLK1 prevents HCC tumor xenograft growth via a microRNA-dependent mechanism. Oncotarget 6: 37200-37215, 2015.

17. Mutoh H, Sashikawa M, Sakamoto $H$ and Tateno T: Cyclooxygenase 2 in gastric carcinoma is expressed in doublecortin- and CaM kinase-like-1-positive tuft cells. Gut Liver 8: 508-518, 2014.

18. Vega KJ, May R, Sureban SM, Lightfoot SA, Qu D, Reed A, Weygant N, Ramanujam R, Souza R, Madhoun M, et al: Identification of the putative intestinal stem cell marker doublecortin and CaM kinase-like-1 in Barrett's esophagus and esophageal adenocarcinoma. J Gastroenterol Hepatol 27: 773-780, 2012.

19. Tamoto A, Yashima K, Hosoda K, Yamamoto S, Kawata S, Ikebuchi Y, Matsumoto K, Kawaguchi K, Harada K, Murawaki Y and Isomoto H: Protein expression of Fragile Histidine Triad and cyclooxgenase-2 in serrated neoplasia of the colorectum. Oncol Lett 14: 3683-3688, 2017.

20. Japanese General Rules for Clinical and Pathological Studies on Cancer of the Colon: Rectum and Anus. Japanese Society for Cancer of the Colon and Rectum, 2009.

21. Schlemper RJ, Riddell RH, Kato Y, Borchard F, Cooper HS, Dawsey SM, Dixon MF, Fenoglio-Preiser CM, Fléjou JF, Geboes K, et al: The Vienna classification of gastrointestinal epithelial neoplasia. Gut 47: 251-255, 2000.

22. Saitoh Y, Waxman I, West AB, Popnikolov NK, Gatalica Z, Watari J, Obara T, Kohgo Y and Pasricha PJ: Prevalence and distinctive biologic features of flat colorectal adenomas in a North American population. Gastroenterology 120: 1657-1665, 2001.

23. Jass JR: Classification of colorectal cancer based on correlation of clinical, morphological and molecular features. Histopathology 50: 113-130, 2007.

24. Mirzaei A, Tavoosidana G, Modarressi MH, Rad AA, Fazeli MS, Shirkoohi R, Tavakoli-Yaraki M and Madjd Z: Upregulation of circulating cancer stem cell marker, DCLK1 but not Lgr5, in chemoradiotherapy-treated colorectal cancer patients. Tumour Biol 36: 4801-4810, 2015.

25. Vedeld HM, Skotheim RI, Lothe RA and Lind GE: The recently suggested intestinal cancer stem cell marker DCLK1 is an epigenetic biomarker for colorectal cancer. Epigenetics 9: 346-350, 2014. 